\title{
Sistematización de un Modelo Fenomenológico-Narrativo para el Análisis del Relato Autobiográfico Durante el Proceso Psicoterapéutico
}

\section{Systematization of a Phenomenological-Narrative Model for the Analysis of Autobiographical Accounts During the Psychotherapeutic Process}

\author{
Dante G. Dueroํ, Francisco Osorio ${ }^{1,2}$, María C. Córdoba ${ }^{1}$ y María del C. González Grané ${ }^{1}$ \\ ${ }^{1}$ Instituto de Investigaciones Psicológicas, Consejo Nacional de Investigaciones \\ Científicas y Técnicas/Facultad de Psicología, Universidad Nacional de Córdoba \\ ${ }^{2}$ Facultad de Ciencias Sociales, Universidad de Chile
}

\begin{abstract}
El artículo se propone caracterizar y sistematizar el método desarrollado por Duero y Limón Arce (2007) para el análisis de relatos autobiográficos. Se trata de un procedimiento fenomenológico y narrativo que procura evaluar la coherencia y composición de esta clase de producción discursiva. Atiende a 2 dimensiones: temático-estructural y funcional. Estos autores han identificado y clasificado estrategias y estilos narrativos para la construcción de relatos autobiográficos de estudiantes universitarios y pacientes con patología mental. Sus datos han mostrado consistencia y han aportado cierta validez inicial al método. El procedimiento habría permitido reconocer patrones narrativos característicos y diferenciados en las distintas submuestras. El procedimiento original ha tenido algunas modificaciones que se han descrito de forma parcial en artículos posteriores, pero no siempre de forma sistemática. Este trabajo ofrece una descripción detallada de las categorías de análisis y etapas del procedimiento, comentando los avances posteriores. Se discute la utilidad del método para investigar qué caracteriza la dinámica y evolución en la construcción del relato autobiográfico de los pacientes en las diferentes etapas de un proceso psicoterapéutico; se aportan datos preliminares en base a trabajos recientes. En estos estudios se ha aplicado el procedimiento en sesiones iniciales y finales de una psicoterapia y en episodios de estancamiento y de cambio terapéutico. Los resultados preliminares indican que las narrativas de los pacientes ofrecen características particulares que el modelo permite reconocer y diferenciar. Se evalúan y discuten las implicancias y potencialidades de la propuesta.
\end{abstract}

Palabras clave: relato autobiográfico, análisis narrativo en psicoterapia, estrategias narrativas, estilos narrativos

This article is aimed at characterizing and systematizing the method developed by Duero and Limón Arce (2007) for the analysis of autobiographical accounts. This is a phenomenological and narrative procedure intended to evaluate the coherence and composition of this kind of discursive production. It considers 2 dimensions: thematic-structural and functional. These authors have identified and classified narrative strategies and styles for the construction of autobiographical accounts by university students and patients with mental pathology. Their data have shown consistency and have provided some initial evidence for the method's validity. The procedure appears to have made it possible to recognize characteristic and differentiated narrative patterns in different subsamples. The original procedure has undergone some modifications over time which have been partially described in subsequent articles, but not always systematically. This study offers a detailed description of the analysis categories and stages of the procedure, along with comments on recent progress. A discussion is presented on the usefulness of the method for characterizing the dynamics and evolution of the autobiographical accounts constructed by patients throughout the psychotherapy process. This discussion is informed by preliminary data based on recent research. In these studies

Dante G. Duero iD https://orcid.org/0000-0001-5332-2896
Francisco Osorio iD https://orcid.org/0000-0002-6326-9061
María C. Córdoba iD https://orcid.org/0000-0003-1967-5991

María del C. González Grané (iD https://orcid.org/0000-0002-2324-3457

En este trabajo se citan a fines ilustrativos datos parciales que han sido publicados en trabajos previos. Entre estos, se consignan algunos de los datos provistos por el Instituto Milenio para la Investigación en Depresión y Personalidad de Santiago de Chile, para la realización de la tesis del segundo autor para optar al grado de Doctor en Psicología de la Universidad de Chile. El trabajo fue financiado por la Secretaría de Ciencia y Técnica de la Facultad de Psicología de la Universidad Nacional de Córdoba, Argentina (Proyecto $\left.\mathrm{N}^{\circ} 33620180100225 \mathrm{CB}\right)$.

La correspondencia relativa a este artículo debe ser dirigida a Francisco Osorio, Instituto de Investigaciones Psicológicas, CONICET/Facultad de Psicología, Universidad Nacional de Córdoba, Argentina, Pabellón de Psicología, Enfermera Gordillo esquina Enrique Barros s/n, Ciudad Universitaria, Córdoba, Argentina-CP 5000. Email: francosovil@yahoo.es 
the procedure have been applied in the initial and final sessions of a psychotherapy and in "stuck" episodes and episodes of therapeutic change. Preliminary results indicate that patients' narratives display particular characteristics that the model allows to recognize and differentiate. The implications and potentialities of the proposal are evaluated and discussed.

Keywords: autobiographical account, narrative analysis in psychotherapy, narrative strategies, narrative styles

Uno de los propósitos de las investigaciones narrativas en el ámbito clínico y psicoterapéutico ha sido aportar a la comprensión de los procesos involucrados en la construcción de los significados personales (Avdi \& Georgaca, 2007; Ramsay, 1998). Según las tesis narrativistas, las narrativas autobiográficas serían una clase de construcción lingüística y discursiva por medio de la cual su autor concatena eventos y construye significados, dando sentido y coherencia a sus experiencias y a sí mismo (Bruner, 1991; McAdams, 2001). Los significados personales surgirían de la capacidad de secuenciar la información experiencial, esto es, organizar los recuerdos y las vivencias personales en forma de relatos y tramas ligadas por ciertos ejes temáticos que les aportan sentido y consistencia (Bruner, 1987, 1991, 1985/2010; Labov \& Waletzky, 1967; Mahoney, 1991, 2003/2005; Neimeyer, 1993, 1995/1998, 2004; Ramsay, 1998; Ricœur, 1983/2004; Wortham, 2001). Algo que ha inquietado a los narratólogos es la posibilidad de desarrollar métodos y procedimientos sistemáticos y efectivos que permitan analizar y clasificar los relatos autobiográficos, reconociendo sus distintos elementos y sus características estructurales. Comprender esto podría muy probablemente ayudarnos a entender de qué modo los sujetos organizan y significan sus experiencias cotidianas y sus propias acciones (Bruner, 1987).

Gonçalves (2002/2002) plantea un esquema de tres dimensiones centrales que sería posible reconocer en cualquier relato autobiográfico: la estructura, el proceso y el contenido narrativo. Estas dimensiones explicarían, respectivamente, el mayor o menor grado de coherencia y la complejidad y diversidad temática que las distintas construcciones narrativas autobiográficas pueden expresar. Numerosos estudios sugieren que niveles bajos de coherencia narrativa parecerían asociarse con menores niveles de salud mental (Adler et al., 2007; Neimeyer \& Raskin, 2000); ciertas formas de desorganización o incoherencia narrativa parecerían estar asociadas con rasgos de personalidad borderline (Adler et al., 2012) o con trastornos como la esquizofrenia (Hermans, 2006; Lysaker \& Lysaker, 2001). El concepto de narrativas prototipo, propuesto por Gonçalves (1995, 2002/2002) para comprender ciertos fenómenos psicopatológicos, alude a formas de organización cognitiva y a procesos de construcción de significado que parecieran ser propios de distintos cuadros. Al parecer, ciertos sesgos se harían evidentes en la forma y el contenido de los relatos de pacientes con patología mental, los cuales tenderían a favorecer temáticas recurrentes y modos de organización rígida al momento de ordenar sus historias personales. Dichos sesgos, por lo demás, restringirían las posibilidades de tener una visión multifacética y dinámica de la propia experiencia y la realidad. La conceptualización de Gonçalves habría sido validada por diferentes estudios mediante los que se identificaron narrativas prototipo de la depresión (Belchior de Sousa \& Pestana Cruz, 2008; Maia, 1998; Neto, 2005), la anorexia (Henriques et al., 2002; Machado et al., 2005) o la tóxicodependencia y el alcoholismo (Fernandes \& Gonçalves, 1997; Gonçalves et al., 1996).

Gonçalves y Machado (2000) han sugerido que el análisis sistemático de las narrativas de los pacientes podría resultar de enorme utilidad como marcador para reconocer indicios de evolución y cambio en la terapia. Por sobre todo, podría ayudar a comprender y esclarecer los procesos mediante los cuales los pacientes reconstruyen y cambian sus significados personales (Gonçalves \& Machado, 1999; McLeod, 2004). Numerosos estudios han propuesto aplicar procedimientos sistemáticos para indagar cómo se producen los cambios en la narrativa y los modos en que los pacientes construyen significados (Avdi \& Georgaca, 2007; McLeod, 2011). Esta clase de herramientas ha permitido identificar distintos indicadores y características particulares en las narrativas de los pacientes durante etapas y segmentos más o menos delimitados del proceso terapéutico o bien como resultado de este proceso. Se ha demostrado, por ejemplo, que tras un proceso terapéutico exitoso, las narrativas de los pacientes expresan mayor multiplicidad de contenido, complejidad narrativa y coherencia narrativa estructural (Botella \& Cutura, 2015; Moreira et al., 2008).

Siguiendo esta propuesta conceptual y atendiendo a la presencia de contenidos excepcionales en la narrativa habitual y problemática de cada paciente, Gonçalves, Ribeiro, Mendes et al. (2011) idearon un Sistema de Codificación de Momentos Innovadores en Psicoterapia. Este permite identificar y rastrear la ocurrencia de diferentes tipos de momentos de innovación (IMS) en la terapia (Gonçalves et al., 2009), que equivaldrían a precursores del cambio terapéutico. Estos pueden aparecer como expresiones que aluden a conductas novedosas, o pensamientos, sentimientos o intenciones que desafían o cuestionan la narrativa 
dominante o sus supuestos (IMS de acción, de reflexión y de protesta, respectivamente). También los IMS pueden identificarse como referencias más explicitas a algún cambio o transformación del paciente entre el pasado y el presente (IMS de reconceptualización) o como la alusión a nuevas experiencias u objetivos personales, a consecuencia del cambio (IMS de realización del cambio). Según afirman los autores, este sistema de análisis ha servido para comprender tanto el cambio terapéutico y el éxito de la psicoterapia, como sus dificultades y fracasos. El cambio aparece como la superación de la autonarrativa problemática, mediante la amplificación y progreso de IMS, especialmente IMS de reconceptualización y realización del cambio, los cuales son predominantes en terapias exitosas (Mendes et al., 2010). El fracaso terapéutico, por el contrario, equivaldría a la mantención de la autonarrativa problemática a causa de la ambivalencia del paciente (Ribeiro et al., 2014; Ribeiro et al., 2015). Esta última operaría mediante la atenuación o neutralización de los IMS por la reaparición de los contenidos problemáticos habituales después de un IM, lo que es más frecuente en casos de pobres resultados terapéuticos (Gonçalves, Ribeiro, Stiles et al., 2011). Cunha et al., 2012 ejemplifican esta ambivalencia: "Me gustaría sentir más confianza para expresarme [IM], pero tengo más miedo que a los demás no les guste de esa forma [reaparición de la voz problemática]" (p. 210).

Desde otra perspectiva y empleando el Sistema de Codificación del Proceso Narrativo (NPCS), Angus et al. (1999) y Angus y Hardtke (1994) reconocieron modos narrativos diferenciados que evidenciarían el nivel de complejidad cognitiva del paciente al momento de referir y ordenar sus propias experiencias. Estos autores constataron en terapias con buen resultado un predominio de modos narrativos reflexivos, por sobre modos narrativos internos (que aluden a experiencias emotivas) y externos (que describen hechos y circunstancias "objetivas"). Con el mismo instrumento, Angus (2012) evidenció, además, que la elaboración de nuevos significados que conducen al cambio terapéutico requiere de un mayor nivel de consciencia y simbolización de contenidos afectivos problemáticos. En estudios más recientes la aplicación del Sistema de Codificación del Proceso Narrativo-Emocional habría permitido establecer igualmente asociaciones entre la narrativa de las emociones y la eficacia terapéutica, mediante marcadores específicos del proceso narrativo emocional, en distintas etapas de la terapia (Angus et al., 2016; Boritz et al., 2014).

Estos y otros procedimientos, como los propuestos por Gonçalves, Henriques y Cardoso (2001), Gonçalves, Henriques, Alves et al. (2001) y Gonçalves, Henriques, Soares et al. (2001), han demostrado ser novedosos, útiles y efectivos para estudiar estos fenómenos. Sin embargo, una de las restricciones que la mayoría de ellos evidencia es que se focalizan sobre aspectos parciales de la narrativa de los sujetos, centrándose por lo general en elementos microestructurales y privilegiando algunas dimensiones por sobre otras. A consecuencia de ello y aún en aquellos casos en que diferentes métodos han sido empleados de modo combinado (e.g., Moreira et al., 2008), cabe preguntarse si no desatienden aspectos globales, intrínsecos del discurso narrativo. Al respecto, hacemos mención a lo que Ricœur (1990/1996, 1983/2004) señala en sus análisis al describir y caracterizar, por ejemplo, la dinámica entre distentio e intentio narrativa o cuando hace alusión al modo en que una y otra condicionan la evolución y la estructura, en términos de trama, de cualquier relato (para una revisión véase Duero 2017, 2019). Algo en lo que Ricœur insiste es en el carácter orgánico, pero asimismo diacrónico y dinámico de cualquier relato o historia.

Otro punto a contemplar es que, aunque los distintos métodos que hemos citado contemplan en sus análisis diferentes niveles jerárquicos, no siempre proporcionan una lectura sobre el modo en que las diferentes dimensiones o categorías podrían estar interactuando unas con otras.

\section{Un Método Fenomenológico-Narrativo para el Análisis del Relato Autobiográfico}

Duero y Limón Arce (2007) y Duero (2010) han desarrollado un método para el análisis fenomenológico y narrativo de relatos autobiográficos, que asegura atender a elementos holísticos y dinámicos, y que considera diferentes niveles de complejidad para el análisis. Inspirándose en una abundante bibliografía, Duero y Limón Arce (2007) han partido identificando diferentes estrategias y dimensiones narrativas presentes en esta clase de relatos, atendiendo, también, al modo en que unas y otras se articulan entre sí. Siguiendo a antecesores como Bruner (1987), estos teóricos creen que el modo en que la narración es configurada determina no solo los marcos de significado, sino también las posibilidades que estos relatos ofrecen para ser reestructurados.

Según Duero y Limón Arce (2007), aún en un proceso como el de la terapia, las posibilidades de intervenciones y cambio estarían dadas a priori, entre otras cosas, por el contenido y el modo en que el relato del paciente ha sido organizado, y por la forma en que ha asegurado su coherencia. La coherencia y los contenidos de la historia, por otra parte, dependerían de diferentes aspectos dinámicos, como el tipo de 
funciones narrativas presentes o la forma en que se organiza la trama en términos temporales. Lo anterior permitiría comprender aspectos clave del proceso de deconstrucción y reconstrucción narrativa que estaría a la base de cualquier proceso que habilite a reestructurar los significados personales, cosa que ocurriría en un trabajo terapéutico exitoso (Dimaggio \& Semerari, 2001).

El método propuesto por Duero y Limón Arce (2007) atiende a dos dimensiones para el análisis de las historias: una temático-estructural y otra funcional. El análisis temático-estructural parte de reconocer los tópicos principales y los acontecimientos significativos de cada relato. Luego, se procede a identificar el marco, nudo, desenlace y consecuencia. Simultáneamente, se atiende a la forma en que son caracterizados los personajes en términos de rasgos, subjetividad, agencia y actancia (Duero \& Córdoba, 2016, 2017). Dentro de la dimensión funcional, estos autores identifican la actividad conclusiva y las funciones de sostén del relato. La actividad conclusiva se refiere a "lo que, con su relato las personas parecen invitarnos a pensar acerca de sí mismas, las demás personas y el mundo" (Duero, 2010, p. 21). Las funciones de sostén, por su parte, se incorporan al relato con la finalidad de amalgamar y apuntalar dicha actividad conclusiva, por ejemplo, en base a justificaciones o explicaciones. De la riqueza y equilibrio de estas funciones de sostén dependería el nivel de coherencia del relato (Duero, 2010; Duero \& Córdoba, 2017). Pero, a la vez, la forma en que la historia es estructurada parecería condicionar qué funciones narrativas se privilegian para apuntalar la trama.

En conjunto, estos elementos permitirían identificar qué estrategias narrativas privilegia una persona al momento de configurar cualquier relato. Aspectos como la integración y completitud de los relatos y su grado de organización, especificidad y clausura podrían depender, sugieren Duero y Limón Arce (2007) —retomando lo propuesto por Fiese \& Sameroff (1999) — de los tipos de estrategias narrativas preferentemente utilizadas al momento de asegurar su composición y coherencia.

Inicialmente, el análisis de estas dimensiones y categorías habría permitido a Duero y Limón Arce (2007), siguiendo propuestas como las de Gergen (1994/1996), identificar distintos estilos o géneros narrativos. Por estilos entendían modos de configurar el desarrollo o trama y de posicionar al héroe de la historia. Diferenciaron, por ejemplo, entre un tipo de relato con propensión a lo trágico-dramático y otro con propensión a lo épico. Ambos ofrecerían una organización diferente, así como rasgos característicos a nivel de la coherencia y composición. Los primeros mostrarían, por ejemplo, a un protagonista víctima de desventuras o un héroe designado colectivamente que debe sortear obstáculos para salvar a un grupo del que forma parte. Dice una entrevistada de 26 años de edad:

Lamentablemente yo a veces he tenido que ocupar el lugar de mamá. Cosa que no me corresponde. Ello me ha hecho olvidar el lugar de hermana (...) Debí ocupar ese lugar porque mi madre estaba muy frágil y mi papá no estaba. (Duero \& Limón Arce, 2007, pp. 261-262; estudiante universitaria en la primera entrevista en profundidad de dos encuentros)

De acuerdo con Duero y Limón Arce (2007), en estos relatos encontramos, a nivel funcional, argumentaciones y justificaciones que dan cuenta del rol que el personaje ocupa dentro de una estructura familiar o comunitaria. Esto ayuda a sostener invariante el estado de la situación, es decir, a bloquear la evolución temporal. A consecuencia de ello, las conclusiones del relato estarán ya parcialmente clausuradas. Dice esta misma entrevistada:

A mí nunca se me hizo una carga [refiriéndose al lugar que debió ocupar]. Siempre lo tomé como una enseñanza (...) Entonces no las tomo como una carga sino como una parte mía. (Duero \& Limón Arce, 2007, p. 262).

Por su lado, caracteriza a los relatos con propensión a lo épico, la presencia del héroe solitario que debe afrontar los avatares del destino. Con una fuerte autoimagen, el protagonista de estas historias surge en un marco que define una situación de desventaja o adversidad a la que logra contraponerse. El siguiente es un extracto del relato de otra entrevistada de 30 años, hablando de su desarrollo personal y profesional:

No es que vengo de una familia que se dedicaba a lo que yo hago. O que tenía una relación cercana. Entonces supongo que tiene que ver con eso lo de reafirmarse. (...) [La mía fue] una formación medio a los golpes (...). (Duero, 2010, p. 101; egresada universitaria en la primera entrevista en profundidad de dos encuentros)

Estos relatos dan la impresión de un constante avance y retroceso y están marcados por las cavilaciones del narrador, quien, a lo largo de la historia, va hallando piezas perdidas que pueden otorgar un nuevo orden al relato. Estas piezas, por lo demás, afianzan el propio sentido de agencia y eficacia del protagonista. Dice esta misma entrevistada:

Desde los 6 años recorto noticias de cine. Era eso, sin saber por qué. Solo juntaba noticias de cine: fotos de diario. O sea, una tontera ¿Porque para qué te sirve una foto del diario? Pero a los 6 años, para algo debe haber servido. 
Y de pronto un día estoy tocándole la puerta a D., diciéndole que quería trabajar en el cineclub que él dirigía. (Duero, 2010, p. 102)

Por otra parte, analizando los relatos de personas con diagnóstico de distintas patologías Soru y Duero (2011), Carreras y Duero (2012) y Duero y Córdoba (2016, 2017) identificaron relatos progresivos, regresivos, de estabilidad (Gergen, 1994/1996) y relatos estancos (Duero \& Córdoba, 2016, 2017). Observaron que los elementos estructurales y funcionales, la actividad conclusiva y el estilo de los relatos se hallaban condicionados por las estrategias narrativas privilegiadas por los entrevistados. En base a esto, sugirieron que sería posible reconocer elementos característicos en los relatos de pacientes en función de sus trastornos (Carreras \& Duero, 2012; Duero \& Carreras, 2015; Duero \& Córdoba, 2017; Soru \& Duero, 2011).

\section{Propuesta}

No obstante la potencial utilidad que el método en cuestión pudiera dejar entrever, un punto que dificulta su adecuada valoración, así como su replicación, es que el modelo ha sido descrito por sus autores de forma parcial y, en ocasiones, poco uniforme en sucesivas publicaciones. Incluso hemos observado algunas variaciones e inconsistencias entre los sistemas de categorías presentados en los distintos trabajos (Carreras \& Duero, 2012; Duero \& Córdoba, 2016, 2017; Duero \& Osorio, 2018; Soru \& Duero, 2011). Así, por ejemplo, las nomenclaturas de las categorías para el análisis de las funciones narrativas empleadas por Duero y Limón Arce (2007) expresan cambios sutiles respecto de lo consignado en trabajos ulteriores, como el de Duero y Osorio (2018). Asimismo, las definiciones teóricas de algunos conceptos (como actividad conclusiva o agencia) también presentan algunas modificaciones. Por otra parte, el hecho de que el sustento empírico derivado de su aplicación se haya limitado, por lo general, al estudio en profundidad de casos únicos o a muestras pequeñas (Carreras \& Duero, 2012; Duero, 2010; Duero \& Carreras, 2015; Duero \& Córdoba, 2016, 2017; Duero \& Osorio, 2018; Soru \& Duero, 2011) nos obliga a subrayar la necesidad de fomentar nuevas investigaciones que ayuden a valorar con mayor exactitud su validez y real utilidad. Por ello, una exposición clara de la propuesta resulta de fundamental importancia para formar nuevos evaluadores y favorecer el trabajo de investigadores que deseen aplicar el modelo.

Atendiendo a todo lo anterior, es que nos propusimos sistematizar y caracterizar el procedimiento. Nos interesa sintetizar sus ideas principales y lo que es esencial de su planteamiento, explicitando en qué aspectos podría diferenciarse de otras propuestas similares. De este modo, la finalidad principal de nuestro desarrollo es ofrecer herramientas que faciliten su comprensión, con vistas a simplificar su aprendizaje y facilitar futuras aplicaciones.

Además, nos interesa discutir las posibilidades del método como herramienta para la exploración del proceso psicoterapéutico. Creemos que el método podría ayudar a estudiar, por ejemplo, la dinámica y evolución del relato autobiográfico de los pacientes a lo largo del proceso de psicoterapia, permitiendo identificar cuáles son las estrategias narrativas que éstos emplean para la construcción de significados en distintas etapas de la terapia o en momentos específicos vinculados con su avance o detención.

\section{Descripción del Método}

El método que Duero y Limón Arce (2007) proponen atiende inicialmente al análisis de: (a) la composición narrativa y (b) la coherencia narrativa de cada relato.

\section{Análisis de la Composición Narrativa (Dimensión Temático-Estructural)}

A fin de analizar la composición y la estructura narrativa, se identifican en primer lugar los nodos temáticos principales y los acontecimientos significativos de la historia, esto es, los tópicos junto con los acontecimientos vitales más importantes en torno a los cuales se desarrolla el relato. Los acontecimientos significativos representan un punto de quiebre o hitos identificables dentro de la historia, por lo general, en base a acciones del protagonista. Con estos acontecimientos es posible construir una línea de tiempo y comenzar a trazar un esbozo del argumento o trama (Duero \& Osorio, 2018; Soru \& Duero, 2011).

Con relación a la trama, se ha diferenciado (a) el marco o situación inicial del relato, que queda definido por el modo en que el autor de la historia caracteriza lo que considera normal o habitual; frente a este reconocen las situaciones atípicas o de conflicto y cambio sobre las que se articula (b) el nudo del relato, que es definido como el conflicto, preocupación o problema central para el narrador, en torno al cual gira el relato; 
(c) el desenlace y (d) la consecuencia. El desenlace nos hablará de la resolución de cada historia y cada microrrelato; puede ser, por ejemplo, la superación de un escollo o la restitución de una pérdida. La consecuencia, por su lado, remitirá a cómo el protagonista queda involucrado dentro el desenlace y a cuáles son las connotaciones que esto tiene para él en términos morales, afectivos o pragmáticos (Duero \& Córdoba, 2017).

El modelo atiende, además, al modo en que son caracterizados el personaje principal y los otros significativos. Los autores identifican distintas modalidades de descripción que, en su conjunto, hacen al carácter de los personajes, esto es, todas las definiciones, referencias o caracterizaciones que el narrador hace acerca de sí mismo y de los otros. Dentro de las mismas, reconocen (a) caracterización por subjetivación, es decir, expresiones que se refieren a vivencias o que aluden al trasfondo psicológico de motivos y razones que justifican los actos y expectativas de cada personaje; (b) caracterización en base a rasgos o atributos más o menos estables; (c) caracterización en base a disposiciones o tendencias a la acción, es decir, actitudes más o menos típicas; (d) caracterización en base a acciones concretas, es decir, referencias a conductas efectivamente realizadas y (e) caracterización en base a la actitud agencial y el rol actancial (Greimas, 1966/1976). La agencia se refiere a la disposición más o menos activa que adoptan el protagonista y los demás personajes de la historia y la actitud actancial, al rol o posición que asumen el protagonista y los demás personajes, unos con relación a otros. Dentro de esta categoría distinguen aquí fundamentalmente las funciones de actantedonante y de paciente-destinatario.

La evolución del relato depende de si el conjunto de los acontecimientos conduce al logro de los objetivos del narrador o a la resolución del nudo. Así, el desarrollo de la trama puede implicar una mejora, desmejora o mantención de la situación vital o estado personal. Las distinciones previas permiten configurar: (a) relatos de tipo progresivo, (b) relatos de tipo regresivo, (c) relatos de estabilidad y (d) relatos estancos; todo ello en función de si, respectivamente, se observa un avance, un retroceso, un recorrido sin altibajos, aunque con una mínima evolución, o bien un detenimiento en la cronología de la historia que lleva del nudo al desenlace (Duero \& Córdoba, 2017; Gergen, 1994/1996; Gergen \& Gergen, 1986).

Una dimensión estrechamente vinculada con la anterior es el tratamiento de la temporalidad en el relato. Esta subdimensión estructural se define por la permanencia o la movilidad y el tránsito de la narración entre pasado, presente y futuro.

\section{Análisis de la Coherencia Narrativa (Dimensión Narrativa Funcional)}

La coherencia de una historia depende principalmente del modo en que las funciones cardinales y de catálisis se ligan entre sí (Barthes, 1966/1991). Depende, entonces, de qué tan explícita y lograda sea la articulación entre los distintos momentos y niveles del relato. Para Duero y Limón Arce (2007) la coherencia de los relatos estaría asegurada, en un nivel primario, por una especie de contrapunto entre la actividad conclusiva y las funciones de sostén (de dicha actividad). Mediante la actividad conclusiva, el autor nos expresa cierta intención narrativa. La misma se hace evidente cuando nos preguntamos ¿por qué o para qué esta persona me cuenta lo que me cuenta? Esta vendría a resumir el conjunto de supuestos que el autor desea transmitirnos sobre él mismo, los otros, el mundo y lo que ha sucedido. Cabe preguntarnos si lo que Duero y Limón Arce (2007) definen como actividad conclusiva no es solo otra forma de nombrar lo que Valdés et al. (2010), al analizar segmentos comunicacionales de sesiones de psicoterapia, llaman intención comunicativa. Corresponde señalar que la noción de actividad conclusiva de Duero y Limón Arce (2007) se inspira en propuestas como las de Bajtín (ca. 1924/1982) y pareciera haber evolucionado a partir de modelos de análisis narratológico formalistas y estructuralistas. Lo que inspira los trabajos de Valdés et al. (2010), en cambio, son los estudios de la pragmática comunicacional (Searle, 1969). Valdés et al. (2010) buscan reconocer elementos performativos del lenguaje y la comunicación, partiendo del análisis de secuencias de interacción conversacional. En este sentido, la intención comunicativa de un acto puntual no necesariamente coincide con la actividad conclusiva que se desprende de un relato como totalidad. El análisis de la actividad conclusiva surge de una mirada comprensiva de todo el relato y depende, entre otras cosas, de la evolución del mismo y del modo en que la trama ordena su diacronía. Un razonamiento parecido se sigue al momento de hacer el análisis de lo que Duero y Limón Arce (2007) llaman funciones de sostén. Aun así, es posible reconocer algunos aspectos comunes en ambas propuestas.

Por otro lado, tenemos las funciones de sostén. Cabe entender que toda historia comienza con un predicado o un conjunto de predicados que introducen un tema y definen una situación. En ocasiones estos predicados iniciales se agrupan con otros que están distribuidos en el relato, dando lugar a lo que Duero y Limón Arce (2007) denominan: comentarios proconclusivos (CPC) y metacomentarios proconclusivos (MCPC). 
Los CPC y los MCPC suelen ser afirmaciones explícitas mediante las cuales el narrador define al protagonista, los otros significativos y al mundo. Hablamos de CPC si lo que se presenta es una afirmación de carácter ontológico o esencialista (dogmático); hablamos, en cambio, de MCPC si lo que se ofrece es un comentario con tono de autointerrogación, opinión o reflexión (doxástico) sobre cómo podrían entenderse o mirarse las cosas.

A los predicados centrales, constituidos generalmente por CPC y/o MCPC, pueden seguirles (o antecederlos): (a) otros conjuntos de predicados que desarrollan un tema (en una secuencia tema-rema) o bien (b) predicados que introducen temas nuevos. Mientras que en el primer caso las distintas proposiciones tienden a amalgamarse, la introducción continua de temas novedosos (es decir, la ausencia de catálisis) desdibuja la posibilidad de configurar una trama y, también, de alcanzar cierta actividad conclusiva (Duero \& Córdoba, 2017).

Junto a los CPC y los MCPC, Duero y Limón Arce (2007) y posteriormente Duero y Córdoba (2016) reconocen las siguientes funciones de sostén:

- Las acotaciones (ACS): (a) las ampliaciones o especificaciones, con las que se brinda más información o se aportan detalles para puntualizar un tema introducido (e.g., "yo soy maestra... maestra jardinera"); (b) las aclaraciones, que hacen más evidente e inteligible alguna particularidad que se pretende visibilizar (e.g., "Cuando digo que estaba cansada, me refiero a que no podía levantarme de la cama") y (c) las ilustraciones y ejemplificaciones, que consisten en la presentación anecdótica de microrrelatos para respaldar lo que se dice (e.g., "Por ejemplo, aquella vez fue al bar y se emborrachó delante de ella").

- Los esquemas génico-causales (EGC): (a) las explicaciones, que son intentos por dar cuenta de un hecho o circunstancia en términos de hechos o factores objetivos determinantes; se refieren a por qué sucedió o tuvo lugar un determinado acontecimiento o acción (e.g., "Mientras alguien le hacía de soporte, él funcionaba"); (b) las interpretaciones, que son intentos por responder a la anterior pregunta en términos comprensivos y adscribiendo al personaje un hipotético conjunto de motivos y razones (e.g., "Él vivía nostálgico y por eso insistía en que regresáramos"); (c) las justificaciones, que tienen un rol persuasivo y responderán a las preguntas "¿por qué lo digo?" o "¿por qué lo hago o lo hice?" (e.g., "Porque si estoy hablando del abandono, es porque estoy tratando de interpretar qué es lo que le pasó").

Duero y Córdoba $(2016,2017)$ sostienen que cuando la actividad conclusiva se apoya en un sistema equilibrado de funciones de sostén, la coherencia y organización que parecen mostrar los relatos es mayor. Cuando las funciones de sostén están presentes no solo en cantidad, sino principalmente en la variedad del tipo de funciones, el relato suele adquirir consistencia y algún grado de clausura pero, también, de apertura para incorporar nueva evidencia o experiencias novedosas (Duero \& Limón Arce, 2007).

\section{El Procedimiento Paso a Paso}

A continuación, intentaremos ilustrar el procedimiento paso a paso, atendiendo a algunas de sus principales dimensiones y categorías. A fin de facilitar la comprensión del modelo señalaremos, antes de cada instancia, si el procedimiento se remite a la dimensión temático-estructural o a la dimensión funcional del análisis. Algunas de las citas las tomamos de transcripciones de entrevistas y sesiones de psicoterapia, ya sea con estudiantes universitarios o con participantes voluntarios con distintos diagnósticos clínicos.

\section{Dimensión Temático-Estructural: Determinar Cuáles Son los Nodos Temáticos Principales}

Los nodos temáticos son tópicos recurrentes que parecieran organizar la narración. A lo largo de una entrevista y de una sesión de terapia, pueden aparecer entre dos y cinco nodos. Ejemplos de estos tópicos son "mi relación de pareja", "mi función como padre", "mi rol docente". El reconocimiento de los nodos temáticos resulta clave al comienzo del análisis, porque permitirá identificar cuáles serán las probables líneas temáticas que estructurarán el relato (Duero \& Limón Arce, 2007).

\section{Dimensión Temático-Estructural: Identificar los Acontecimientos Vitales Significativos}

Intrínsecamente vinculados a los nodos temáticos, están los acontecimientos vitales significativos, esto es, eventos que representan un punto de quiebre dentro de la historia: "la vez que me mudé", "la vez que fui infiel", "la ocasión en que pegué a mi hijo", "cuando enfermé", "cuando me separé". 


\section{Dimensión Funcional: Identificar la Actividad Conclusiva}

Tras una lectura atenta y global del material, lo que se intenta es identificar la actividad conclusiva que se desprende de las distintas partes del relato. ¿Qué nos invita a concluir el narrador sobre sí mismo, el mundo y los otros personajes? Esta pregunta nos permitirá ir reconociendo actividades conclusivas parciales que luego han de integrarse en una conclusión más global considerando la totalidad del relato. Citamos a continuación un párrafo de una entrevista, en el que la actividad conclusiva es bien explícita:

En un momento me doy cuenta de que estaba viviendo una vida prestada. Yo me había vuelto dependiente.

Entonces empecé a reconocer mis grietas. Empecé a obligarme a pensar más en mí mismo. Pero tenía que superar mis miedos, miedo a estar solo. (Hombre de 29 años, paciente en tratamiento, sesión psicoterapéutica número 2 de 22 sesiones)

El narrador expresa con relativa claridad lo que piensa acerca de sí mismo y nos da una idea bastante definida acerca de su mundo vital.

El extracto que transcribimos a continuación ilustra, en cambio, la presentación de una serie de posibles nodos problemáticos en los que es difícil dilucidar una actividad conclusiva (relato con escasa coherencia). Esto, en parte, es consecuencia de que el entrevistado se limita a hacer ciertas afirmaciones sin desarrollarlas y de que pareciera pasar de uno a otro tema:

En el último tiempo aumentó el desgano. No sé por qué. Estoy terminando el curso de aviación. Tengo que empezar a volar. Pueden ser nervios... ahora mamá... ya se terminó de olvidar. Un mes atrás vos podías mantener una conversación moderada, digamos. Ahora ya no. Le digo: "Mamá, soy Marcelo". "Ah, sí. ¿A qué viniste?"... Es raro. Lo primero, vos como que la quedas mirando y decís: "Bueno, tenía que pasar". Por otro lado, no sabes si llorar o estar contento. Porque como ella se siente bien así, pienso yo... No sabes qué hacer. (Hombre de 24 años, paciente en tratamiento, sesión psicoterapéutica número 1 de 32 sesiones)

\section{Dimensión Temático-Estructural: Identificar Cómo Está Caracterizado el Personaje}

La caracterización de cada personaje puede realizarse, inicialmente, a partir de rasgos y disposiciones o de procesos que describen una dinámica, es decir, modos circunstanciales de estar o de sentir, acciones concretas, entre otros. Asimismo, para la caracterización pueden emplearse expresiones objetivantes o bien expresiones que remarquen los aspectos subjetivos del personaje. El siguiente es un ejemplo de una caracterización hecha en base a rasgos y disposiciones más o menos permanentes:

Me considero una persona bastante alegre, también me considero una persona tímida. Bueno, una descripción que hacía un amigo mío hace tiempo y me pareció muy acertada, es que soy muy tímido más no serio, como que tímido, tengo la reserva. ¿Qué más? Pues, me considero una persona tenaz en las cosas que hago, comprometido con lo que me gusta y me interesa. (Hombre de 22 años, estudiante universitario, primera entrevista en profundidad de dos encuentros)

En este ejemplo abundan los predicados que designan rasgos estables o disposiciones. Por otro lado, la presencia de expresiones mentales como "me gusta", "me interesa", hacen suponer una cierta acentuación del elemento subjetivo, así como una consideración por los aspectos dinámicos, cambiantes o procesales.

El análisis de la caracterización es importante para reconocer aspectos identitarios del protagonista y de los otros significativos. Así, por ejemplo, si un entrevistado tiende a definirse a sí mismo y a los otros a partir de rasgos estables, predominará una perspectiva más bien rígida sobre los aspectos de su personalidad y cómo estos influyen en las decisiones y los actos diarios. Por el contrario, una mirada de los personajes y sus conductas mayormente ordenada sobre aspectos circunstanciales conllevará una perspectiva más heterodoxa y cambiante sobre los aspectos identitarios, pero a riesgo de que con ello el relato pierda consistencia.

\section{Dimensión Temático-Estructural: Reconocer la Posición Agencial y los Roles Actanciales del Protagonista y los Otros Personajes}

El siguiente paso es el análisis de la agencia y la actancia. El análisis de la agencia requiere atender a aquellas expresiones que se refieren a acciones concretas, a disposiciones a la acción y, también, al carácter más o menos motivado de tales actos. Una actitud agencial puede ser predominantemente pasiva y respondiente, o bien activa. Veamos un ejemplo de lo que sería una agencia empobrecida:

Estoy como con el freno de mano puesto, estoy así como paralizada, esto me tiene paralizada, como que no logro...

(Mujer de 32 años, paciente en tratamiento, sesión psicoterapéutica número 1 de 31 sesiones) 
Respecto de la actitud actancial, la misma permite identificar roles y funciones que definen el tipo de vínculo entre los personajes. Las funciones de actante-donante y de paciente-destinatario serían prototípicas. El siguiente sería un ejemplo de un posicionamiento actancial como paciente-destinatario:

Mi esposo es súper dominante, una persona que está acostumbrada a que toda su vida él ha dirigido. (Mujer de 42 años, paciente en tratamiento, sesión psicoterapéutica número 13 de 20 sesiones)

Un rol actante-donante se ve en este otro ejemplo:

Siempre ha dependido de mí, les he dado todo. (Mujer de 64 años, paciente en tratamiento, sesión psicoterapéutica número 1 de 20 sesiones)

\section{Dimensión Funcional: Identificar los Comentarios Pro-Conclusivos (CPC) y los Metacomentarios Pro-Conclusivos (MCPC)}

El análisis del nivel funcional del relato en sus distintas etapas requiere de tareas de codificación de los segmentos de estudio, permitiendo asignar a estos las distintas categorías funcionales (CPC, MCPC, ACS, EGC) y la variedad de predicados que detallaremos más adelante. Como dijimos, los CPC y MCPC resumirían intentos por definir, caracterizar y enmarcar la realidad. Pero mientras que los CPC son afirmaciones "objetivantes" (e.g., "todos los hombres son desconfiados, porque creen que una hace lo que ellos hacen"), los MCPC son un conjunto de interpretaciones, reflexiones o interrogaciones que relativizan lo concluido (e.g., "Tal vez yo no sepa darme un lugar. Me pregunto si no debiera revisar esa forma mía de ser y actuar").

Los CPC y MCPC, así como el resto de las funciones de sostén, se enuncian mediante distintos tipos de predicados. Estos son los predicados (a) ontológicos y existenciales de estado (POE), que caracterizan una situación en términos de permanencia (e.g., "Yo soy impulsivo", "estoy en un estado de anhedonia"); (b) deontológicos (PD), que definen cómo debieran ser las cosas (e.g., "si uno tiene un hijo debe ocuparse de su crianza"); (c) circunstanciales y frecuentativos (PCF), que aluden a acciones y acontecimientos específicos (e.g., "Ayer por la tarde lo llamé por teléfono y le dije: necesito que hablemos") o que se refieren a la frecuencia con que se realizan ciertas actividades o acciones (e.g., "dedico una gran cantidad de horas a ese club"); (d) proféticos, contrafácticos y de posibilidad (PPP), que hacen referencia a cosas que podrían pasar o que podrían haber pasado (e.g., "si hubiese quedado embarazada, yo hoy estaría más confiada y sin este rótulo"); (e) existenciales de devenir (PEDev), que se refieren un proceso de cambio en la vida del personaje (e.g., "desde que me di cuenta que le estaba dando mi vida a mi trabajo, comencé a mirar más a mi familia"); (f) existenciales de decisión (PED), que remarcan una toma de posición respecto de una situación (e.g., "he decidido separarme"); (g) predicados subjetivantes (PS), esto es, expresiones que utilizan verbos mentales y que hacen referencia a vivencias y estados subjetivos internos (e.g., "creo que", "me parece que", "siento que", "deseo que"); (h) predicados evaluativos (PE); (i) interpretativos (PI), que suponen una valoración o una interpretación respecto de un acontecimiento, conducta o circunstancia. (Duero \& Córdoba, 2017; Duero \& Limón Arce, 2007).

La mayoría de los predicados permite indicar una connotación positiva o negativa. Además, en el caso de los PE y los PI, es posible connotar adicionalmente si tienen o no un carácter reflexivo (PE o PI Ref) (ver Tabla 1).

Luego de identificar los CPC y MCPC, Duero y Limón Arce (2007) (véase también la reformulación de Duero y Córdoba (2016) proponen atender a si los mismos se siguen o son precedidos por ACS o EGC, registrando, a su vez, los tipos de predicados que los conforman. Veamos un ejemplo:

Se trata de una mujer de 35 años que participó como voluntaria (trabajadora informal, entrevista en profundidad (primera de dos encuentros). Comienza su relato con un predicado introductorio en base a un POE: "Soy Fabiana, estoy sola en Buenos Aires". Luego ofrece una ACS (ampliación o especificación): "decidí venirme"; esto es, emplea un PED al que complementa con un EGC (justificación) y un PCF: "luego de muchas situaciones tristes". Con esto ha definido su situación actual: está sola porque decidió venirse debido a situaciones tristes. Dice después: "es como que... digamos... me quedé sola... me dejaron sola". Este último predicado (POE) funciona como un CPC: "soy/estoy sola porque así me dejaron otros". A continuación, la entrevistadora pregunta: "¿Quiénes?". Ella aporta una ACS (ampliación o especificación); de este modo suma coherencia y consistencia a la historia en base a otro POE: "Y... mi familia anexa, o sea la familia extendida... pero mi familia cercana no", tras lo cual justifica, utilizando un PCF: "con ellos pasaron otras cosas". Después propone una nueva ACS (ampliación o especificación), empleando un PCF y un POE: "A ver... te hago un panorama general, mi familia se compone de mi papá que está geriatrizado, porque tuvo un ACV, mi mamá que está fallecida y una media hermana con la que no me hablo desde que a mi papá le dio el ACV...". Agrega 
entonces otra ACS (ampliación o especificación) que puede a la vez funcionar también como EGC (justificación) mediante un POE: "y como no soy de acá, no tengo familia, tampoco tengo novio, hijos, esas cosas no... nada". Finalmente, dice, empleando un CPC (articulado sobre PE, PS y PED): "Yo sé lo que es tener una familia complicada y sufrir por eso... padecerlos... y enfermarme... por eso, prefiero estar sola que rodeada de gente chata, interesada".

Como vemos, las sucesivas ACS y EGC vienen a funcionar como apoyo de los CPC. Con ello, el relato va adquiriendo cierta clausura que, a su vez, justifica el predicado existencial de decisión final (que funciona como CPC). La actividad conclusiva que de ello se desprende es: "Soy/estoy sola, porque así me dejaron otros. Ahora prefiero estar sola".

Tabla 1

Códigos de los Componentes Funcionales

\begin{tabular}{ll}
\hline Componente funcional & \multicolumn{1}{c}{ Categorías y códigos } \\
\hline \multirow{2}{*}{ Actividad conclusiva } & Comentarios proconclusivos (CPC) \\
& Metacomentarios proconclusivos (MCPC) \\
Funciones de sostén & $\begin{array}{l}\text { Acotaciones (ACS): ampliaciones, especificaciones, aclaraciones, ilustraciones o } \\
\text { ejemplificaciones }\end{array}$ \\
& Esquemas génico-causales (EGC): explicaciones, interpretaciones, justificaciones \\
& Predicado ontológico y existencial de estado (POE), \\
& Predicado deontológico (PD) \\
& Predicado circunstancial y frecuentativo (PCF) \\
& Predicado profético, contrafáctico y de posibilidad (PPP) \\
& Predicado existencial de devenir (PEDev) \\
& Predicado existencial de decisión (PED) \\
& Predicado subjetivante (PS) \\
& Predicado interpretativo (PI) \\
& Predicado interpretativo reflexivo (PI Ref) \\
& Predicado evaluativo (PE) \\
& Predicado evaluativo reflexivo (PE Ref) \\
\hline
\end{tabular}

\section{Elaboración de una Síntesis Narrativa}

Una vez realizado el análisis temático-estructural y funcional del relato, se hace una síntesis del argumento. Para esto se confecciona un esquema a partir de dos ejes, uno diacrónico y otro sincrónico. Esto supone distribuir la información referida a los diferentes episodios significativos y las acciones de los personajes dentro una línea temporal, y atender al modo recurrente en que se caracterizan los personajes y las situaciones en los diferentes momentos. En base a ambos ejes se procura esquematizar los principales vectores a partir de los cuales se ordena la narrativa autobiográfica analizada (Carreras \& Duero, 2012; Soru \& Duero, 2011). A partir de lo anterior, se hace posible reconocer el estilo o género narrativo predominante (progresivo, regresivo, de estabilidad o estanco).

En la Tabla 2 presentamos un esquema sintético de todas las categorías y pasos del método.

\section{Discusión y Conclusiones}

\section{Originalidad: Comparación con otras Propuestas}

Algo a determinar es: ¿en qué medida la propuesta que acabamos de presentar es verdaderamente novedosa y en qué grado podría ser útil para complementar la información de modelos de análisis precedentes, como los revisados? Algo reconocible es que las distinciones que este procedimiento propone parecen mostrar puntos en común con algunas de las investigaciones citadas. Así, por ejemplo, las distinciones de Angus et al. (1999) y Angus y Hardtke (1994) con el NPCS sobre los modos narrativos (externo, interno y reflexivo), presentan cierto nivel de convergencia con algunas de las categorías que posteriormente 
desarrollaran Duero y Limón Arce (2007), al reconocer los distintos tipos de predicados y su implicancia para la configuración de las diferentes partes de una historia. Dicho de otra forma, el modo externo, asociado a la descripción de eventos, correspondería parcialmente al menos con lo que estos autores reconocen en los PCF (y eventualmente como ilustraciones y ejemplificaciones, en términos de ACS), por un lado, pero, también, con lo que identifican como POE. El modo interno, por otra parte, estaría relacionado con la descripción de sentimientos, sensaciones y reacciones subjetivas y parecería asociarse con un predominio de PS y PEDev (Duero \& Osorio, 2018). El modo reflexivo, finalmente, aparecería vinculado con la elaboración cognitiva, el insight y la resignificación, y pareciera tener su equivalencia en lo que Duero y Limón Arce (2007) y, posteriormente, Duero y Osorio (2018) identificaran como PI, PE, PPP y PED, encontrándose, adicionalmente, asociados con los MCPC.

\section{Tabla 2}

Secuencia de Pasos en las Categorías y Dimensiones de Análisis

\begin{tabular}{|c|c|}
\hline Dimensión de análisis & Pasos y categorías de análisis \\
\hline $\begin{array}{l}\text { Análisis de la composición y la estructura } \\
\text { narrativa (dimensión temático-estructural) }\end{array}$ & $\begin{array}{l}\text { 1. Caracterización de tópicos principales } \\
\text { 2. Caracterización de los acontecimientos significativos y la } \\
\text { temporalidad. En base a ello, caracterización de (a) marco (b) } \\
\text { nudo (c) desenlace y las consecuencias del relato }\end{array}$ \\
\hline $\begin{array}{l}\text { Análisis de la coherencia narrativa (dimensión } \\
\text { funcional) }\end{array}$ & $\begin{array}{l}\text { 3. Identificación de la actividad conclusiva en base a una primera } \\
\text { lectura global del relato }\end{array}$ \\
\hline $\begin{array}{l}\text { Análisis de la composición y la estructura } \\
\text { narrativa (dimensión temático-estructural) }\end{array}$ & $\begin{array}{l}\text { 4. Caracterización de los personajes en base a (a) subjetivación, } \\
\text { (b) disposiciones y rasgos, (c) conductas. } \\
\text { 5. Caracterización de la posición agencial y los roles actanciales } \\
\text { de los personajes }\end{array}$ \\
\hline $\begin{array}{l}\text { Análisis de la coherencia narrativa (dimensión } \\
\text { funcional) }\end{array}$ & $\begin{array}{l}\text { 6. Identificación, codificación y caracterización de las funciones } \\
\text { de sostén a la actividad conclusiva (CPC y MCPC; EGC y ACS; } \\
\text { tipos de predicados) }\end{array}$ \\
\hline En base al análisis de ambas dimensiones & $\begin{array}{l}\text { 7. Elaboración de una síntesis narrativa (reajustando la } \\
\text { actividad conclusiva y delimitando el estilo o género narrativo } \\
\text { predominante) }\end{array}$ \\
\hline
\end{tabular}

Nota. CPC: comentarios proconclusivos; MCPC: metacomentarios proconclusivos; EGC: esquemas génico-causales; ACS: acotaciones.

En síntesis, es difícil negar cierta correspondencia entre las categorizaciones de ambos modelos. Podríamos suponer que una y otra propuesta usan denominaciones distintas para referir fenómenos y procesos semejantes. Visto con más detalle, sin embargo, quizá la diferencia principal de ambos enfoques tenga que ver con que Angus et al. (1999) y Angus y Hardtke (1994) parecieran estar atendiendo al tipo de proceso cognitivo que subyace y da cuenta de algunos de los contenidos que expresan las historias. Si preguntáramos ¿a qué se debe que en este relato prevalezca un modo externo?, la respuesta sería: a una forma de procesamiento de información que el sujeto privilegia, la cual se evidencia en sus construcciones narrativas. Angus et al. (1999) y Angus y Hardtke (1994) atienden al relato como modo de expresión de ciertas formas de procesar cognitivamente la información, dejando en segundo plano la naturaleza narrativa y diacrónica de estas construcciones discursivas. Duero y Limón Arce (2007), en cambio, parecieran asumir, junto con Bruner (1987, 1991) o Ricœur (1978-1998/1999), que las estrategias narrativas expresan modalidades primarias de cognición que en sí ya son intrínsecamente narrativas (véase Duero, 2017, 2019). Un estilo interno, por ejemplo, sería resultado de una modalidad narrativa particular que condiciona la forma en que la experiencia es, entre otras cosas, temporalmente ordenada y significada.

Al desatender lo que podrían ser los elementos diacrónicos, Angus et al. (1999) y Angus y Hardtke (1994) no nos dicen mucho sobre cómo podrían interactuar, por ejemplo, los distintos elementos procesales que ellas reconocen, con respecto de otros factores, como el argumento, el modo en que los distintos personajes se relacionan, los roles que ocupan unos respecto de otros o, incluso, el desenlace y la conclusión que se desprende de la historia. Empleando su modelo, inferiríamos que el estilo de un paciente es más o menos interno, externo, reflexivo o mixto, pero aplicando el modelo de Duero y Limón Arce (2007), quizá podríamos 
reconocer, además, por ejemplo, cuáles son las estrategias que pacientes con un modo interno, externo y reflexivo privilegian para garantizar la composición y la coherencia de sus relatos o también de qué modo esto condiciona el contenido, su dinámica y su estructura e, incluso, el grado de apertura y coherencia de la historia.

Ilustremos lo dicho, analizando el siguiente extracto. El mismo ha sido tomado de una sesión de terapia. Se trata de una mujer de 64 años, quien desde un comienzo intenta enmarcar su historia de vida y la problemática que la lleva a consultar e iniciar la terapia. Dice:

Entonces, yo me jubilé a mediana edad. Había decidido no tener hijos, porque no era apta como madre. Y por esas cosas de la vida me da a esta niñita que no hice. Los primeros 8 años de vida de esta niñita hice todo lo que pude para apoyarla. (Sesión psicoterapéutica número 1 de 20 sesiones)

Desde la propuesta de las autoras, muy posiblemente fuera factible reconocer en esta transcripción elementos de un estilo externo ("me jubilé a mediana edad", "no era apta como madre", "la vida me da esta niñita") y también, de forma sutil, de un estilo interno, aunque con tintes reflexivos ("había decidido no tener hijos"). ¿Qué obtendríamos, en cambio, al aplicar el modelo de Duero y Limón Arce (2007)? En términos estructurales, el segmento viene a definir y caracterizar el marco de la historia. Podemos presumir que, muy probablemente, la historia adquirirá desde el comienzo una tonalidad heroica con componentes trágicos: "Había decido no tener hijos por no ser apta como madre"; "la vida me da esta niñita", "hice todo lo que pude para apoyarla". Es decir: el relato se ordenará como un esfuerzo del personaje principal para sobreponerse a las circunstancias. En términos de caracterización, la protagonista es hasta aquí definida en base a rasgos negativos ("no ser apta como madre"), pero también a aspectos agenciales que sugieren actividad y propósito ("había decidido no tener hijos", "la vida me da esta niñita que no hice"; "hice todo lo que pude para apoyarla"). No hay prácticamente referencias explícitas a aspectos subjetivos de tipo emotivo o afectivo. En el plano actancial, observamos una tendencia a definir vínculos en términos asimétricos de donante-receptor ("la vida me da esta niñita que no hice"; "hice todo lo que pude para apoyarla").

Atendiendo a cómo ha sido configurado el marco, tal vez podríamos especular sobre la evolución y el tipo de actividad conclusiva que el relato permitiría presumiblemente construir más adelante: (a) o bien la historia adquirirá la dinámica de un relato progresivo, en el que la protagonista intentará demostrarnos cómo, gracias al esfuerzo y a consecuencia de su decisión, consigue sobreponerse a las contingencias y los desafíos que la vida le plantea; (b) o bien nos invitará a ver cómo, pese a su disposición valiente y a su voluntad, la fatalidad se impone y la obliga a transitar un derrotero (con lo cual el relato pasará a adquirir una tonalidad de drama o tragedia). De ocurrir esto último, la historia tendrá escasa evolución temporal y una prospectiva más bien cerrada y con desenlace negativo.

Respecto a la coherencia, observamos, en términos de predicados, una prevalencia de PCF que remiten a hechos o circunstancias ("me jubilé a mediana edad", "la vida me da a esta niñita que no hice", "los primeros 8 años de vida de esta niñita hice todo lo que pude para apoyarla"), de POE ("no era apta como madre") y PED ("había decidido no tener hijos"), que son empleados para autocaracterizarse. No hay PS, PE, PI ni PPP. Con relación a las funciones, en este extracto es posible reconocer CPC ("Los primeros 8 años de vida de esta niñita hice todo lo que pude para apoyarla"), EGC que funcionan como explicación o justificación ("Había decidido no tener hijos porque no era apta como madre") y algunas ACS ("la vida me da a esta niñita que no hice", "los primeros 8 años de vida de esta niñita hice todo lo que pude para apoyarla"). La ausencia de EGC interpretativos, por lo demás, no ha de sorprendernos, faltando los PS, PE y PI.

En un plano heurístico y predictivo, lo anterior nos permite elaborar una serie de hipótesis bastante sencillas y factibles de ser contrastadas. Por ejemplo, es factible que esta paciente tienda a privilegiar una actividad conclusiva más bien clausurada y que busque definir a la protagonista y los demás personajes en base a rasgos rígidos y más o menos permanentes o en términos de la eficacia con la que actúan y los logros que consiguen alcanzar; es también probable que los elementos subjetivos sean más bien pobres y negativos.

Por otra parte, también resulta probable que en los vínculos se repitan situaciones que conlleven a vivencias de injusticia y frustración. En el plano de las funciones, es asimismo factible que se repita la tendencia a emplear PCF, POE y PED, junto con CPC (y quizá EGC justificativos y explicativos) que inviten a clausurar la historia. Volveremos sobre este caso en el apartado posterior. 


\section{Utilidad para Estudiar el Proceso de Terapia}

Pasando a otro punto, nos preguntamos si el procedimiento podría ofrecer herramientas de análisis útiles para la exploración de los procesos de reestructuración de los marcos de significado de los pacientes, como los que tienen lugar durante el proceso psicoterapéutico.

$\mathrm{Al}$ respecto, cabe mencionar que en los últimos dos años hemos obtenido alguna evidencia preliminar aplicando el modelo para analizar fragmentos de las narrativas de pacientes procedentes de momentos específicos del proceso terapéutico (Duero \& Osorio, 2018; Osorio Villegas, 2019). Hemos estudiado y comparado sesiones de etapas evolutivamente diferenciadas de la terapia (por ejemplo, sesiones iniciales y finales del proceso), así como microrrelatos de segmentos de sesión vinculados con momentos de detención y estancamiento de la misma - episodios de estancamiento (EE; Fernández et al., 2012; Valdés \& Krause, 2015) — en relación a episodios de cambio terapéutico (EC; Krause et al., 2002; Valdés \& Krause, 2015). Según pudimos observar, los modos en que se configuran las narrativas del paciente durante estas sesiones y de estos tipos de episodio sugieren la operación de factores y procesos específicos y diferenciados, tanto para la construcción de los significados problemáticos del paciente, como en la reestructuración de los mismos. Expondremos algunos hallazgos preliminares obtenidos a partir de estos estudios.

En el primero de estos trabajos (Duero \& Osorio, 2018) realizamos un análisis de las narrativas autobiográficas de la primera y la última sesión de una psicoterapia. Se trata de la misma paciente del ejemplo anterior: mujer de 64 años, soltera, jubilada, con diagnóstico de depresión, con una mejoría significativa tras la terapia, verificada en los puntajes del OQ-45.2 (von Bergen \& de la Parra, 2002). El análisis global de la sesión inicial evidenció que en los planos temático y estructural el relato se centraba en aspectos circunstanciales y sobre temáticas recurrentes. La autocaracterización era en base a rasgos, mostraba una baja autorreferencia y una subjetivación empobrecida y mayormente negativa; la agencialidad era confusa y expresaba una vivencia de pérdida del sentido de eficacia. En el plano actancial prevalecían los vínculos asimétricos con los demás. En conjunto, el relato mostraba escasa evolución y poca diferenciación entre marco, nudo y desenlace. Ya a nivel de las funciones narrativas, se evidenciaba un predominio de CPC por sobre los MCPC, así como una actividad conclusiva cerrada, sostenida en el plano funcional por EGC explicativos rígidos y objetivantes.

Durante la última sesión, en cambio, la paciente mostró una narrativa más rica, compleja y también más coherente. En el nivel temático y estructural se observó el desarrollo de problemáticas nuevas y más variadas; en términos de autocaracterización, se observó una mayor autorreferenciación y subjetivación, junto con una forma novedosa y más activa de agenciación que reforzaba el sentido de autoeficacia. En el plano actancial los roles se volvían más simétricos. La trama expresaba, asimismo, una mayor evolución temporal, en donde el marco, nudo y desenlace se veían mejor diferenciados. A nivel funcional, parecían disminuir los CPC e incrementarse los MCPC. También parecían disminuir los EGC con explicaciones rígidas y objetivantes, apareciendo interpretaciones que habilitaban a pensar la experiencia en términos dinámicos y multifacéticos. En general, esto mismo habilitaba una actividad conclusiva más flexible, pero también más integrada, en el sentido de que permitía configurar significativamente un mayor número de elementos de la historia (Duero \& Osorio, 2018). Es decir, las narrativas de la primera y última sesión evidenciaron modificaciones en términos de composición y coherencia, expresando hacia el final del tratamiento mayor integración, complejidad y riqueza, y una mejor propensión a construir marcos de significado novedosos. Esto coincidiría con lo propuesto por autores como Stiles et al. (1999), quienes afirman que el cambio terapéutico reflejaría un proceso de reconstrucción de significados, por el que ciertas experiencias problemáticas logran ser exitosamente asimiladas a los esquemas del paciente, estableciendo nuevos puentes entre diferentes voces y narrativas, posibilitando procesos de autoorganización más exitosos.

Nuestro segundo estudio (Osorio Villegas, 2019) se enfocó en el análisis de EE. Estas narrativas fueron comparadas con EC. Para ello, trabajamos sobre una muestra de cuatro pacientes adultas que completaron un proceso de psicoterapia exitosa de entre 20 y 30 sesiones. Jueces entrenados identificaron los EE y EC, atendiendo a criterios observacionales y basándose en las expresiones verbales del paciente durante las sesiones (Programa Chileno de Investigación en Psicoterapia y Cambio. Versión 2.0, 2012). Se seleccionó un total de 12 EE y 12 EC (tres episodios de cada tipo por caso).

Los siguientes fueron algunos de nuestros principales hallazgos. Comparativamente, durante los EE (y con relación a los EC), se observó: (a) una mayor heterorreferencia al momento de caracterizar y atribuir los factores causales de los nodos problemáticos; (b) una mayor insistencia en referir acontecimientos 
negativos asociados con sentimientos de impotencia e imposibilidad; (c) una menor diferenciación del marco respecto del nudo, el cual se extiende e inunda toda la trama; (d) la ausencia de un desenlace o resolución clara; (e) una menor evolución de la trama; (f) una caracterización de la protagonista en términos de rasgos rígidos y una subjetivación pobre y mayormente negativa; (g) una agencia y una actancia que expresan, respectivamente, un posicionamiento pasivo y una relación asimétrica con el otro; (h) en el plano de las funciones predominaban los CPC junto con los EGC del tipo de las justificaciones, por sobre los MCPC y los EGC interpretativos (propios de los EC) e (i) en conjunto, la actividad conclusiva era más cerrada y se hallaba restringida a considerar diversos factores y puntos de vista.

Como ha señalado Osorio Villegas (2019), esta clase de resultados parecieran sugerir, entre otras cosas, que durante los EE se impondría una actividad conclusiva clausurada que limitaría la incorporación de elementos novedosos del proceso terapéutico en la narrativa personal de su autor. Este efecto, a su vez, parecería resultar de estrategias narrativas de orden temático-estructural y funcional más específicas, las que serían subsidiarias, por ejemplo, del tipo de predicados y de la clase de funciones de sostén privilegiadas por el paciente.

Algunos de estos resultados son comparables con los reportados por el equipo de Gonçalves (Gonçalves et al., 2009; Mendes et al., 2010), cuando trabajan con nociones como los IMS y la ambivalencia, por ejemplo. Por ello, volveremos a preguntar: ¿Qué aporta este nuevo procedimiento con respecto al de este autor y su equipo y qué distingue a uno y otro modelo teórico y metodológico? Como hemos venido observando, ambos enfoques propician en esencia un análisis multidimensional de las narrativas autobiográficas del paciente, atendiendo a sus elementos estructurales y al tipo de contenido del que los relatos se nutren. Pero la propuesta de análisis de Gonçalves y sus colaboradores (Gonçalves et al., 2009; Mendes et al., 2010) pareciera centrarse mayormente en niveles estructurales microanalíticos de la secuencia de contenidos de las historias. Es decir, se focaliza en elementos temáticos y estructurales más discretos, así como en el efecto semiótico que dichos contenidos tienen - en términos, por ejemplo, de atenuación o amplificación de la discrepancia respecto de la narrativa problemática del paciente - con los efectos subsecuentes en la supresión o maximización de elementos precursores del cambio terapéutico (Gonçalves, Ribeiro, Stiles et al., 2011).

El modelo presentado, en cambio, atiende a los elementos compositivos de cada historia desde los niveles micro, pero incorporando también otros aspectos macroestructurales y una perspectiva dinámica del conjunto. Esto mismo ha permitido, por ejemplo, evidenciar aspectos no identificados con otros sistemas de análisis, tales como las características de la temporalidad y la evolución de la historia, y el modo en que todo ello discute con los demás factores, como el tipo de funciones narrativas predominantes o, incluso, el estilo narrativo (Osorio Villegas, 2019).

\section{Principales Fortalezas}

Entre las fortalezas diferenciales del método que presentamos, según nuestra opinión, es que permite realizar un análisis pormenorizado de los distintos elementos compositivos que condicionan la arquitectura de los relatos autobiográficos, al tiempo que proporciona una mirada de conjunto de la historia como totalidad significativa, atendiendo para ello a una concepción y un método propiamente narrativista. Aunque muchos de los procedimientos de otros autores están centrados en el análisis de relatos, no todos ellos contemplan ni aseguran una mirada propiamente narrativa al momento de conceptualizar esta clase de producción discursiva específica (Avdi \& Georgaca, 2007).

Según mostramos antes, el procedimiento establece un análisis por niveles que considera las distintas dimensiones y categorías y el modo en que se superponen. Una consecuencia positiva de ello es que las expresiones del entrevistado son exhaustivamente codificadas. Esto, a la vez, permitiría reconocer posibles relaciones entre dimensiones y categorías e identificar estilos.

Una vez más nos valdremos de otro ejemplo. El segmento corresponde a la sesión seis de un tratamiento de 31 sesiones. La paciente es una mujer de 32 años con diagnóstico de depresión. En este primer segmento, el tópico se centra sobre una entrevista de trabajo mantenida días atrás. Dice:

[ACS/AMPLIA (PS)] Se me quitaron todos los entusiasmos en el fondo cuando me dijo que me iban, a que iba a trabajar en una tienda de ropa y te pagaban el mínimo. [ACS/ ACLARA (PS/PE)] fue como, o sea, fue como súper decepcionante... [(PS)]: yo no estaba muy convencida, poco entusiasmada. [EGC/JUSTIFICA (PS o PED)] Entonces, tampoco [me] quiero presentar, porque igual decir, oh, me tengo que levantar temprano, igual me da lata. [EGC/JUSTIFICA (PED o PS)] Pero sé que tengo que trabajar y quiero trabajar, pero no quiero tampoco y en este minuto tampoco me puedo poner muy regodeona [complacerse en lo que le gusta]. 
Si nos atenemos a la cita, en términos estructurales este segmento describe una situación problemática que puede ser codificada como parte del nudo y que se extiende hacia el marco de la historia. Este último sugiere una situación precaria, de inestabilidad económica y laboral, que condiciona la vida de la protagonista durante un período que se sostiene en el tiempo. En la caracterización del personaje prevalece una tendencia a referir experiencias subjetivas o estados afectivos de ambivalencia. Si observamos el trasfondo de motivos y razones, la paciente no define ni identifica con claridad expectativas o deseos. En términos de agencia expresa una actitud pasiva; prima la indecisión y la contrariedad. En el plano actancial, describe una situación asimétrica. Dentro de la categoría otros significativos, el otro aparece caracterizado únicamente como alguien que no se ajusta a sus expectativas. En términos de funciones, se privilegia el nivel descriptivo por sobre el reflexivo. Hay dos ACS y un EGC (justificación). Si nos centramos en el tipo de predicados, reconocemos un predominio de PS (con contenido emotivo y connotación negativa).

Es fácil suponer que, si durante segmentos anteriores y posteriores de la historia se repitieran los patrones identificados hasta aquí, esta paciente tenderá, por ejemplo, a (a) describir el nudo como parte del marco de la historia, (b) privilegiar su autocaracterización en términos subjetivos, predominantemente refiriéndose a estados afectivos negativos que son "provocados" por otros; (c) expresar una agencia pasiva, marcada por sentimientos de impotencia e indecisión; (d) referir una actancia asimétrica, en la que ella se ubica como demandante frustrada; (e) realizar una caracterización pobre de los otros, atendiendo especialmente al modo en que aquel satisface o no sus expectativas y demandas; (f) hacer un uso frecuente en el plano de las funciones de ACS y EGC (justificaciones) y (g) en el plano de los predicados, privilegiar el uso de PS (con valencia negativa). Todo ello condicionará un modo de configurar y sostener la actividad conclusiva y a definir su posicionamiento como personaje principal.

El siguiente segmento corresponde a otro momento de la terapia de esta misma paciente (extraído al azar de la sesión siete). En él la paciente se refiere a ciertas dificultades para sostener vínculos estables de pareja y a los conflictos con uno de sus pretendientes. Citamos:

[EGC/JUSTIFICA (PS/POE o PCF)] [Y es que esas cosas] eran las que no me gustaban: que él fuera una persona dependiente, que él dependiera de mí, que no tuviera una red de amigos que lo protegiera, que lo apoyara, que si yo no estaba o no estaba su señora o la "polola" que fuera, él estaba solo en el universo, [ACS/AMPLIA (PCF)] de que empezara a llamarme un domingo a las 8 y media de la mañana, me [da] rabia, pues. [EGC/JUSTIFICA (PS o PE, con valencia negativa)] Encuentro que es estúpido. ¿Cómo no se da cuenta? es como, o sea, ni yo llamo a las 8 y media de la mañana, salvo que me pase una emergencia a mi familia a un amigo, o sea...

En este nuevo segmento observamos, primero, que la paciente (a) vuelve a describir el nudo como parte de una historia de inestabilidad, que pertenece al marco, es decir, una situación de conflicto que se ha mantenido irresuelta en el tiempo; (b) en el plano de la autocaracterización, privilegia la referencia a estados subjetivos, pero especialmente de tipo afectivo negativo, por ejemplo, "[Y es que esas cosas] eran las que no me gustaban"; (c) en el nivel de la agencia, predomina una actitud pasiva, que expresa un estado de impotencia, pasividad y frustración: "me [da] rabia, pues, encuentro que es estúpido"; (d) en el plano actancial, vuelven a surgir roles asimétricos, ella se ubica como quien ve frustradas sus expectativas: "No me gustaba; me [da] rabia que él fuera una persona dependiente, que él dependiera de mí", aunque aquí el otro se muestra como destinatario o receptor, también es definido como quien no da; (e) el otro aparece caracterizado, únicamente, como aquel que genera insatisfacción y que no se adecua a las expectativas de ella: "¿Cómo no se da cuenta...?"; (f) a nivel de las funciones, emplea generalmente ACS (ampliaciones) y EGC (justificaciones) y (g) en el plano de los predicados, privilegia el uso de PS o PE (con valencia negativa). Es decir, se repiten elementos y se reproduce un estilo semejante al del primer fragmento.

En síntesis y en base a lo ilustrado, creemos factible que el método revisado podría servir para ayudar a identificar estrategias en el relato del paciente que puedan asociarse a patrones y estilos narrativos más globales y recurrentes, que en ocasiones pudieran interferir en la apropiación y reconstrucción de nuevos significados durante el proceso terapéutico. Al permitir identificar patrones narrativos característicos, el modelo podría ayudar no solo a reconocer, sino también a predecir modos problemáticos de significación del paciente. Por otro lado, la posibilidad de reconocer dichos patrones narrativos problemáticos alerta sobre la factibilidad de identificar quiebres o giros en los mismos, como hitos a consignar que sean favorables al proceso de cambio terapéutico. 


\section{Principales Limitaciones}

Algunas limitaciones de la propuesta derivan del enfoque teórico y epistemológico del modelo, producto del encuentro de la narrativa con la fenomenología y la hermenéutica (Gadamer, 1976; Gonçalves, 2002/2002; Ricœur, 1990/1996, 1983/2004). Se trata de un modelo de carácter eminentemente interpretativo. Es decir, el codificador debe considerar que cada segmento y cada expresión pueden ser codificados desde múltiples niveles, atendiendo a las distintas categorías y dimensiones. Su aplicación requiere, por esta misma razón, de un proceso previo de entrenamiento con vistas a que el evaluador aprenda a identificar y clasificar las distintas expresiones y segmentos. Es, además, necesario contrastar el proceso de codificación entre diferentes investigadores. El tiempo preciso que lleva la codificación, por lo otro lado, no es menor, dependiendo de la extensión y la complejidad del material a codificar y de la habilidad y entrenamiento del investigador.

En cuanto a las etapas para el aprendizaje del modelo, el entrenamiento progresivo para que un evaluador novel pueda familiarizarse y aplicarlo por sí mismo, puede estimativamente implicar un trabajo de al menos tres meses (con unas 20 horas de trabajo semanal); el mismo comienza con un acercamiento que permita al estudiante familiarizarse con los supuestos teóricos y epistemológicos, reconocer prototipos de cada categoría, llevar a cabo sucesivos ensayos con segmentos característicos para familiarizarse con el proceso de codificación, atendiendo al principio a unas pocas categorías y, finalmente, aplicar una codificación exhaustiva y hacer un análisis posterior a entrevistas o sesiones completas, bajo una supervisión intensiva periódica.

Como un punto adicional, cabe decir que la complejidad del análisis dificulta su aplicación en muestras numerosas. En tal aspecto, otros modelos, como los citados en apartados previos, son más efectivos y eficientes cuando se trata de analizar muestras grandes.

Con relación a su empleo en el ámbito clínico, algo a observar es que la complejidad del mismo impide aplicarlo para el análisis periódico y sistemático de todas las sesiones de terapia. Sin embargo, creemos que en algunos momentos clave, como, por ejemplo, al iniciar un tratamiento, la aplicación de esta metodología podría evidenciar estilos y estrategias narrativas típicas.

A nivel técnico o procedimental, una limitación adicional del método es que opera con criterios de análisis aplicables solo a transcripciones escritas. Es posible que con ello se descuiden factores importantes, como aquellos vinculados con la información no verbal que se da durante la interacción entre paciente y terapeuta durante una psicoterapia. Otra consideración o debilidad del modelo es que su diseño original se enfoca principalmente en la narrativa del entrevistado o el paciente, según corresponda y no del entrevistador o terapeuta. Dada la realidad intersubjetiva del encuentro terapéutico, pudiera ser necesario incluir las intervenciones del profesional.

\section{Líneas Futuras}

Las aplicaciones previas del método permiten contar con una gama de criterios sobre aspectos observables en la narrativa de los pacientes durante la terapia, los cuales cabría investigar como marcadores o hitos críticos en la evolución y el tránsito en dicho proceso de cambio personal. En base a esto podría proponerse una línea de investigación más definida, que adopte una perspectiva orientada al descubrimiento de episodios significativos o relevantes para la terapia (Elliot, 2012; Fritzpatrick \& Chamodraka, 2007). Esto posibilitaría la indagación de dichos segmentos para comprender mejor los aspectos específicos que facilitan o, por el contrario, que dificultan la reconstrucción de los significados y la mejoría del paciente.

Una interrogante que se desprende es en qué grado y cómo los procedimientos y el estilo propio de cada terapeuta podrían facilitar o, por el contrario, obstaculizar habilidades, estilos o, incluso, determinados contenidos y estrategias narrativas de los pacientes que pudieran favorecer la terapia. Evidencia robusta sugiere que el modo en que las personas significan sus experiencias depende en gran medida del tipo de interacción y el tipo de audiencia a la que se dirigen cuando relatan y reconstruyen sus historias personales. Moreira et al. (2011) han mostrado, por ejemplo, que las respuestas de una misma paciente frente a las intervenciones de terapeutas con distintas orientaciones se modifican y que esto se expresa en sus narrativas. Estos autores aplicaron un sistema de codificación de tres dimensiones (estructura, proceso y contenido de los relatos) y compararon entre sí las narraciones de una misma paciente durante tres sesiones frente a tres profesionales diferentes (de orientación humanista, gestáltica y cognitivo-conductual, respectivamente). Sus datos dejan entrever diferencias significativas para las tres dimensiones analizadas, en función de qué terapeuta llevó a cabo la sesión. El nivel de complejidad narrativa, reflexividad y variedad de contenido en el relato de la paciente, por ejemplo, pareció ser mayor durante la sesión con el terapeuta humanista. Esto dio 
lugar a una actitud más reflexiva, mayor conexión con su experiencia subjetiva, una mayor predisposición a adoptar puntos de vistas alternativos y mayor actividad de síntesis por parte de la paciente. Los relatos surgidos durante la sesión con el terapeuta cognitivo-conductual, por otra parte, resultaron ser los menos ricos y elaborados. Es decir, los resultados de este trabajo parecieran sugerir una correlación entre el estilo de cada terapeuta y la narrativa resultante de cada sesión.

\section{Referencias}

Adler, J. M. (2012). Living into the story: Agency and coherence in a longitudinal study of narrative identity development and mental health over the course of psychotherapy. Journal of Personality and Social Psychology, 102(2), 367-389. https://doi.org/10.1037/a0025289

Adler, J. M., Chin, E. D., Kolisetty, A. P. \& Oltmanns, T. F. (2012). The distinguishing characteristics of narrative identity in adults with features of borderline personality disorder: An empirical investigation. Journal of Personality Disorders, 26(4), 498-512. https://doi.org/10.1521/pedi.2012.26.4.498

Adler, J. M., Wagner, J. W. \& McAdams, D. P. (2007). Personality and the coherence of psychotherapy narratives. Journal of Research in Personality, 41(6), 1179-1198. https://doi.org/10.1016/j.jrp.2007.02.006

Angus, L. (2012). Toward an integrative understanding of narrative and emotion processes in emotion-focused therapy of depression: Implications for theory, research and practice. Psychotherapy Research, 22(4), 367-380. https://doi.org/10.1080/10503307.2012.683988

Angus, L., Boritz, T., Bryntwick, E., Carpenter, N., Macaulay, C. \& Khattra, J. (2016). Narrative-Emotion Process Coding System manual (NEPCS). Versión 2.0 FV. York University, Faculty of Health, Department of Psychology, Angus Narrative-Emotion Marker Lab.

Angus, L. \& Hardtke, K. (1994). Narrative processes in psychotherapy. Canadian Psychology, 35(2), 190-203. https://doi.org/10.1037/0708-5591.35.2.190

Angus, L., Levitt, H. \& Hardtke, K. (1999). The narrative processes coding system: Research applications and implications for psychotherapy practice. Journal of Clinical Psychology, 55(10), 1255-1270. https://doi.org/10.1002/(SICI)1097-4679(199910)55:10<1255::AID-JCLP7>3.0.CO;2-F

Avdi, E. \& Georgaca, E. (2007). Narrative research in psychotherapy: A critical review. Psychology and Psychotherapy: Theory, Research and Practice, 80(3), 407-419. https://doi.org/10.1348/147608306X158092

Bajtín, M. M. (1982). Estética de la creación verbal (T. Bubnova, Trad.). Siglo XXI. (Obra original publicada ca. 1924)

Barthes, R. (1991). Introducción al análisis estructural de los relatos. En E. Verón \& S. Niccolini (Comps.), El análisis estructural del relato (B. Dorriots, Trad.; pp. 65-101). Centro Editor de América Latina. (Obra original publicada en 1966)

Belchior de Sousa, A. \& Pestana Cruz, J. (2008). Narrativa protótipo da depressão [Narrativa prototipo de la depresión]. Mudanças Psicologia da Saúde, 16(1), 71-80. https://doi.org/10.15603/2176-1019/mud.v16n1p71-80

Boritz, T. Z., Bryntwick, E., Angus, L., Greenberg, L. S. \& Constantino, M. J. (2014). Narrative and emotion process in psychotherapy: An empirical test of the Narrative-Emotion Process Coding System (NEPCS). Psychotherapy Research, 24(5), 594-607. https://doi.org/10.1080/10503307.2013.851426

Botella, L. \& Cutura J. M. (2015). Narrative processes in psychotherapy: Differences between good and poor outcomes clients. Acción Psicológica, 12(2), 123-142. https://doi.org/10.5944/ap.12.2.15766

Bruner, J. (1987). Life as narrative. Social Research, 54(1), 11-32. https://ewasteschools.pbworks.com/f/Bruner_J_LifeAsNarrative.pdf

Bruner, J. (1991). The narrative construction of reality. Critical Inquiry, 18(1), 1-21. https://doi.org/10.1086/448619

Bruner, J. (2010). Realidad mental y mundos posibles: los actos de la imaginación que dan sentido a la experiencia (B. López, Trad.). Gedisa. (Obra original publicada en 1985)

Carreras, X. \& Duero, D. G. (2012). Sentimiento de orientación vital y vivencia del cuerpo en personas con trastornos de la alimentación: un estudio fenomenológico-narrativo. Revista Argentina de Ciencias del Comportamiento, 4(3), 30-47. https://doi.org/10.32348/1852.4206.v4.n3.5165

Cunha, C., Gonçalves, M. M., Valsiner, J., Mendes, I. \& Ribeiro, A. P. (2012). Rehearsing renewal of identity: Reconceptualization on the move. En M. -C. Bertau, M. M. Gonçalves \& P. T. F. Raggat (Eds.), Dialogic formations: Investigations into the origins and development of the dialogical self (pp. 205-233). Information Age Publishing.

Dimaggio, G. \& Semerari, A. (2001). Psychopathological narrative forms. Journal of Constructivist Psychology, 14(1), 1-23. https://doi.org/10.1080/107205301451335

Duero, D. G. (2010). Coherencia y composición en el relato autobiográfico: estrategias para su análisis e implicancias para la psicoterapia. Revista CES Psicología, 3(2), 18-47. https://doi.org/10.21615/1213

Duero, D. G. (2017). ¿Por qué la narrativa importa a la psicología? Thémata: Revista de Filosofía, 55, 131-156. https://doi.org/10.12795/themata.2017.i55.06

Duero, D. (2019). La narrativa como modalidad básica de cognición: aportes narratológicos a la ciencia psicológica. Límite: Revista Interdisciplinaria de Filosofía \& Psicología, 14, Artículo 11. https://doi.org/10.4067/S0718-50652019000100211

Duero, D. G. \& Carreras, X. (2015). Un análisis fenomenológico y narrativo de los "Diarios" de la escritora Alejandra Pizarnik. Athenea Digital: Revista de Pensamiento e Investigación Social, 15(1), 31-63. https://doi.org/10.5565/rev/athenea.1044

Duero, D. G. \& Córdoba, M. C. (2016). Análisis comparativo de los estilos narrativos de personas con síntomas depresivos y obsesivocompulsivos. Revista Peruana de Psicología y Trabajo Social, 5(1), 27-51. https://doi.org/10.32544/psicologia.v5i1.135

Duero, D. \& Córdoba M. C. (2017). Análisis fenomenológico narrativo de una persona con diagnóstico de trastorno obsesivo compulsivo, reconsideraciones sobre el cuadro clínico. Anuario de Investigaciones de la Facultad de Psicología, 3(1), $264-283$. https://revistas.unc.edu.ar/index.php/aifp/article/view/18104/18507

Duero, D. G. \& Limón Arce, G. (2007). Relato autobiográfico e identidad personal: un modelo de análisis narrativo. AIBR: Revista de Antropología Iberoamericana, 2(2), 232-275. https://doi.org/10.11156/aibr.020205

Duero, D. G. \& Osorio Villegas, F. J. (2018). Phenomenological-narrative contributions to understand the narrative strategies that shape the autobiographical account throughout different moments of the therapeutic process. Research in Psychotherapy: Psychopathology, Process and Outcome, 21(2), 232-275. https://doi.org/10.4081/ripppo.2018.309

Elliot, R. (2012). Qualitative methods for studying psychotherapy change processes. En D. Harper \& A. R. Thompson (Eds.), Qualitative research methods in mental health and psychotherapy: An introduction for students and practitioners (pp. 69-81). Whiley-Blackwels. https://doi.org/10.2010.1002/9781119973249.ch6 
Fernandes, E. \& Gonçalves, O. F. (1997). Exploração de constructos pessoais sobre o self em mudança em pacientes depressivos e agorafóbicos [Exploración de los constructos personales sobre el yo en transformación en pacientes depresivos y agorafóbicos]. Psicologia: Teoria, Investigação e Prática, $2, \quad 33-52$. http://repositorium.sdum.uminho.pt/bitstream/1822/4203/1/Explora\%c3\%a7\%c3\%a3o\%20de\%20Construtos\%20Pessoais\%20sobre \%20o\%20self\%20em\%20mudan\%c3\%a7a\%20em\%20pacientes\%20depressivos\%20e\%20agoraf\%c3\%b3bicos.pdf

Fernández, O., Herrera, P., Krause, M., Pérez, J. C., Valdés, N., Vilches, O. \& Tomicic, A. (2012). Episodios de cambio y estancamiento en psicoterapia: características de la comunicación verbal entre pacientes y terapeutas. Terapia Psicológica, 30(2), 5-22. https://doi.org/10.4067/S0718-48082012000200001

Fiese, B. H. \& Sameroff, A. J. (1999). The family narrative consortium: A multidimensional approach to narrative. Monographs of the Society for Research in Child Development, 64(2), 1-36. https://doi.org/10.1111/1540-5834.00017

Fitzpatrick, M. R. \& Chamodraka, M. (2007). Participant critical events: A method for identifying and isolating significant therapeutic incidents. Psychotherapy Research, 17(5), 622-627. https://doi.org/10.1080/10503300601065514

Gadamer, H. -G. (1976). Philosophical hermeneutics. University of California Press.

Gergen, K. J. (1996). Realidades y relaciones: aproximaciones a la construcción social (F. Meler Orti, Trad.). Paidós Ibérica. (Obra original publicada en 1994)

Gergen, K. J. \& Gergen, M. M. (1986). Narrative form and the construction of psychological science. En T. R. Sarbin (Ed.), Narrative psychology: The storied nature of human conduct (pp. 22-44). Praeger.

Gonçalves, M. M., Matos, M. \& Santos, A. (2009). Narrative therapy and the nature of "innovative moments" in the construction of change. Journal of Constructivist Psychology, 22(1), 1-23. https://doi.org/10.1080/10720530802500748

Gonçalves, M. M., Ribeiro, A. P., Mendes, I., Matos, M. \& Santos, A. (2011). Tracking novelties in psychotherapy process research: The innovative moments coding system. Psychotherapy Research, 21(5), 497-509. https://doi.org/10.1080/10503307.2011.560207

Gonçalves, M. M., Ribeiro, A. P., Stiles, W. B., Conde, T., Matos, M., Martins, C. \& Santos, A. (2011). The role of mutual in-feeding in maintaining problematic self-narratives: Exploring one path to therapeutic failure. Psychotherapy Research, 21(1), 27-40. https://doi.org/10.1080/10503307.2010.507789

Gonçalves, O. F. (1995). Psicoterapia cognitivo-narrativa: la construcción hermenéutica de los significados alternativos. Revista de Psicoterapia, 6(22-23), 101-122. https://tienda.revistadepsicoterapia.com/psicoterapia-cognitivo-narrativa-la-construccionhemerneutica-de-los-significados-alternativos.html

Gonçalves, O. F. (2002). Psicoterapia cognitiva narrativa: manual de terapia breve (M. Fernández Prieto, Trad.). Desclée de Brouwer. (Obra original publicada en 2002)

Gonçalves, O. F., Alves, A. R., Soares, I. \& Duarte, Z. T. (1996). Narrativas prototipo y psicopatología: un estudio con pacientes alcohólicos, anoréxicas y opiáceo-dependientes. Revista de Psicopatología y Psicología Clínica, 1(2), 105-114. https://doi.org/10.5944/rppc.vol.1.num.2.1996.3813

Gonçalves, O. F., Henriques, M., Alves, R. \& Rocha, C. (2001). Narrative process and complexity evaluation manual [Manuscrito no publicado]. Departamento de Psicologia, Universidade do Minho.

Gonçalves, O. F., Henriques, M. R. \& Cardoso, G. (2001). Narrative structural and coherence evaluation manual [Manuscrito no publicado]. Departamento de Psicologia, Universidade do Minho.

Gonçalves, O. F., Henriques, M., Soares, L. \& Monteiro, A. (2001). Narrative content and multiplicity evaluation manual [Manuscrito no publicado]. Departamento de Psicologia, Universidade doMinho.

Gonçalves, O. F. \& Machado, P. P. P. (1999). Cognitive narrative psychotherapy: Research foundations. Journal of Clinical Psychology, 55(10), 1179-1191. https://doi.org/10.1002/(SICI)1097-4679(199910)55:10\%3c1179::AID-JCLP2\%3e3.0.CO;2-L

Gonçalves, O. F. \& Machado, P. P. P. (2000). Emotions, narrative and change. European Journal of Psychotherapy \& Counselling, 3(3), 349-360. https://doi.org/10.1080/13642530010012002

Greimas, A. J. (1976). Semántica estructural: investigación metodológica (A. de la Fuente, Trad.). Gredos. (Obra original publicada en 1966)

Henriques, M. R., Machado, B. C. \& Gonçalves, O. F. (2002). Anorexia nervosa: a validação divergente de uma narrativa protótipo [Anorexia nerviosa: una validación divergente de una narrativa prototipo]. International Journal of Clinical and Health Psychology, 2(1), 91-109. https://www.redalyc.org/pdf/337/33720105.pdf

Hermans, H. J. M. (2006). The self as a theater of voices: Disorganization and reorganization of a position repertoire. Journal of Constructivist Psychology, 19(2), 147-169. https://doi.org/10.1080/10720530500508779

Krause, M., Aristegui, R. \& de la Parra, G. (2002). Hacia una práctica efectiva de la psicoterapia: un estudio de episodios de cambio en diferentes tipos de psicoterapia y su relación con los resultados psicoterapéuticos. Proyecto FONDECYT $N^{\circ} 1030482$ [Manuscrito no publicado]. Escuela de Psicología, Pontificia Universidad Católica de Chile.

Labov, W. \& Waletzky, J. (1967). Narrative analysis. En J. Helm (Ed.), Essays on the verbal and visual arts: Proceedings of the 1966 Annual Spring Meeting of the American Ethnological Society (pp. 12-44). University of Washington Press.

Lysaker, P. H. \& Lysaker, J. T. (2001). Psychosis and the disintegration of dialogical self-structure: Problems posed by schizophrenia for the maintenance of dialogue. British Journal of Medical Psychology, 74(1), 23-33. https://doi.org/10.1348/000711201160777

Machado, B. C., Gonçalves, Ó. F., Machado, P. P. P., Henriques, M. R., Brandão, I. \& Roma-Torres, A. (2005). Anorexia nervosa e construção de significado: validação divergente de uma narrativa protótipo [Anorexia nerviosa y construcción de significado: una validación divergente de una narrativa prototipo]. Comportamento Alimentar, 2(4), 1-12. http://repositorium.sdum.uminho.pt/bitstream/1822/3022/1/Anorexia\%20Nervosa\%20e\%20Constru\%c3\%a7\%c3\%a3o\%20de\%20Sig nificado_Valida\%c3\%a7\%c3\%a30\%20divergente\%20de\%20uma\%20narrativa\%20prot\%c3\%b3tipo.pdf

Mahoney, M. J. (1991). Human change processes: The scientific foundations of psychotherapy. Basic Books.

Mahoney, M. J. (2005). Psicoterapia constructiva: una guía práctica (V. Comañ, Trad.). Paidós Ibérica. (Obra original publicada en 2003)

Maia, A. D. C. (1998). Narrativas protótipo e organização no conhecimento na depressão [Narrativas prototipo y organización del conocimiento en la depresión] [Tesis de doctorado, Universidade do Minho]. RepositóriUM Universidade do Minho. http://hdl.handle.net/1822/586

McAdams, D. P. (2001). The psychology of life stories. Review of General Psychology, 5(2), 100-122. https://doi.org/10\%2010371/1089-2680.5.2.100

McLeod, J. (2004). Social construction, narrative and psychotherapy. En L. E. Angus \& J. McLeod (Eds.), The handbook of narrative and psychotherapy: Practice, theory and research (pp. 351-366). SAGE. https://doi.org/10.4135/9781412973496.d26

McLeod, J. (2011). Qualitative research in counselling and psychotherapy (2a ed.). SAGE. https://doi.org/10.4135/9781849209663 
Mendes, I., Ribeiro, A. P., Angus, L., Greenberg, L. S., Sousa, I. \& Gonçalves, M. M. (2010). Narrative change in emotion-focused therapy: How is change constructed through the lens of the innovative moments coding system? Psychotherapy Research, 20(6), 692-701. https://doi.org/10.1080/10503307.2010.514960

Moreira, P., Beutler, L. E. \& Gonçalves, O. F. (2008). Narrative change in psychotherapy: Differences between good and bad outcome cases in cognitive, narrative, and prescriptive therapies. Journal of Clinical Psychology, 64(10), 1181-1194. https://doi.org/10.1002/jclp.20517

Moreira, P., Gonçalves, O. F. \& Matias, C. (2011). Clients' narratives in psychotherapy and therapist's theoretical orientation: An exploratory analysis of Gloria's narratives with Rogers, Ellis and Perls. Journal of Cognitive and Behavioral Psychotherapies, 11(2), 173-190. https://www.researchgate.net/publication/232275321_Clients' narratives_in psychotherapy and therapist's theoretical orientati on_An_exploratory_analysis_of_Gloria's_narratives_with_Rogers_Ellis_and_Perls

Neimeyer, R. (1993). An appraisal of constructivist psychotherapies. Journal of Consulting and Clinical Psychologist, 61(2), 221-234. https://doi.org/10.1037/0022-006X.61.2.221

Neimeyer, R. A. (1998). Las narrativas generadas por el cliente en psicoterapia. En R. A. Neimeyer \& M. J. Mahoney (Comps.), Constructivismo en psicoterapia (A. Aparicio, Trad.; pp. 219-235). Paidós Ibérica. (Obra original publicada en 1995)

Neimeyer, R. A. (2004). Fostering posttraumatic growth: A narrative contribution. Psychological Inquiry, 15(1), 53-59. https://www.jstor.org/stable/20447202?seq=1

Neimeyer, R. A. \& Raskin, J. D. (2000). Constructions of disorder: Meaning-making frameworks for psychotherapy. American Psychological Association. https://doi.org/10.1037/10368-000

Neto, M. L. R. (2005). O discurso e as narrativas na vivência da depressão [Discursos y narrativas en la experiencia de depresión]. Psicologia, Saúde \& Doenças, 6(2), 131-138. http://www.redalyc.org/articulo.oa?id=36260202

Osorio Villegas, F. J. (2019). Construcción narrativa problemática durante episodios de estancamiento en psicoterapias de pacientes con depresión, según subtipos clínicos anaclítico e introyectivo [Tesis de doctorado, Universidad de Chile]. Repositorio Académico de la Universidad de Chile. http://repositorio.uchile.cl/handle/2250/171488

Programa Chileno de Investigación en Psicoterapia y Cambio. Versión 2.0. (2012). Manual de observación, registro y codificación de episodios de cambio y estancamiento. Instituto Milenio para la Investigación en Depresión y Personalidad (MIDAP). https://midap.org/wp-content/uploads/2015/06/manual_cambio_y_estancamiento.pdf

Ramsay, J. R. (1998). Postmodern cognitive therapy: Cognitions, narratives, and personal meaning-making. Journal of Cognitive Psychotherapy, 12(1), 39-55. https://doi.org/10.1891/0889-8391.12.1.39

Ribeiro, A. P., Gonçalves, M. M., Silva, J. R., Brás, A. \& Sousa, I. (2016). Ambivalence in narrative therapy: A comparison between recovered and unchanged cases. Clinical Psychology \& Psychotherapy, 23(2), 166-175. https://doi.org/10.1002/cpp.1945

Ribeiro, A. P., Mendes, I., Stiles, W. B., Angus, L., Sousa, I. \& Gonçalves, M. M. (2014). Ambivalence in emotion-focused therapy for depression: The maintenance of problematically dominant self-narratives. Psychotherapy Research, 24(6), 702-710. https://doi.org/10.1080/10503307.2013.879620

Ricœur, P. (1996). Sí mismo como otro (A. Neira, Trad.). Siglo XXI. (Obra original publicada en 1990)

Ricœur, P. (con Gabilongo, A. \& Aranzueque, G.). (1999). Historia y narratividad (G. Aranzueque Sahuquillo, Trad.). Paidós Ibérica. (Obras originales publicadas en 1978-1998)

Ricœur, P. (2004). Tiempo y narración Vol. I: Configuración del tiempo en el relato histórico (5a ed.; A. Neira, Trad.). Siglo XXI. (Obra original publicada en 1983)

Searle, J. R. (1969). Speech acts: An essay in the philosophy of language. Cambridge University Press. https://doi.org/10.1017/CBO9781139173438

Soru, M. F. \& Duero, D. G. (2011) Experiencias corporales y sentimiento de orientación vital: una aproximación fenomenológica y narrativa. Pensando Psicología, 7(13), 59-74. https://revistas.ucc.edu.co/index.php/pe/article/view/392/393

Stiles, W. B., Honos-Webb, L. \& Lani, J. A. (1999). Some functions of narrative in the assimilation of problematic experiences. Journal of Clinical Psychology, 55(10), 1213-1226. https://doi.org/10.1002/(SICI)1097-4679(199910)55:10<1213::AID-JCLP4>3.0.CO;2-1

Valdés, N. \& Krause, M. (2015). Verbal expressions used by anaclitic and introjective patients with depressive symptomatology: Analysis of change and stuck episodes within therapeutic sessions. Clínica y Salud, 26(2), 103-119. https://doi.org/10.1016/j.clysa.2015.06.001

Valdés, N., Tomicic, A., Pérez, J. C. \& Krause, M. (2010). Sistema de Codificación de la Actividad Terapéutica (SCAT 1.0): dimensiones y categorías de las acciones comunicacionales de pacientes y psicoterapeutas. Revista Argentina de Clínica Psicológica, 19(2), 117-130. https://www.academia.edu/16628241/Sistema_de_Codificaci\%C3\%B3n_de_la_Actividad_Terap\%C3\%A9utica_SCAT_1_0_Dimensione s_y_categor\%C3\%ADas_de_las_acciones_comunicacionales_de_pacientes_y_psicoterapeutas_Therapeutic_Activity_Coding_System_

Von Bergen, A. \& de la Parra, G. (2002). Cuestionario para evaluación de resultados y evolución en psicoterapia: adaptación, validación e indicaciones para su aplicación e interpretación OQ-45.2. Terapia Psicológica, 20(2), 161-176. https://www.researchgate.net/publication/263314562_OQ452 CUESTIONARIO PARA EVALUACION_DE RESULTADOS_Y_EVOLUCION_EN_PSICOTERAPIA ADAPTACION_VALIDACION_E_I NDICACIONES PARA SU APLICACION E INTERPRETACION OQ-452 AN OUTCOME QUESTIONNAIRE FOR MONITORING_CH

Wortham, S. (2001), Narrative self-construction and the nature of self. En S. Wortham (Ed.), Narratives in action: A strategy for research and analysis (pp. 136-156). Teachers College Press.

Fecha de recepción: Diciembre de 2018.

Fecha de aceptación: Agosto de 2020. 